\title{
The impact of latest changes in Financial Reporting on Stakeholders' Confidence and Satisfaction.
}

\begin{abstract}
This paper focuses on how the latest changes in corporate financial reporting have an impact on the stakeholders i.e. the shareholders, employees, management, creditors, auditors, suppliers andthe public in general. Financial information serves as an important input and guide for informed decision making in an economic environment.The financial statements are one of the most important bases on which the internal and external stakeholders reach effective decisions. The idea of "General Purpose Financial Reporting" is directed to the common information needs of users and stakeholders. This study attempts to assess whether the stakeholder's confidence and satisfaction is enhanced by the nature and extent of information that is made available to the stakeholders and the practices of corporate disclosure in annual accounts.

Keywords - corporate financial reporting,the stakeholders, financial statements,stakeholder's confidence and satisfaction.

This paper focuses on how the latest changes in corporate financial reporting have an impact on the stakeholders i.e. the shareholders, employees, management, creditors, auditors, suppliers andthe public in general. Financial information serves as an important input and guide for informed decision making in an economic environment.The financial statements are one of the most important bases on which the internal and external stakeholders reach effective decisions. The idea of "General Purpose Financial Reporting" is directed to the common information needs of users and stakeholders. This study attempts to assess whether there is any impact onstakeholder's confidence by the nature and extent of information that is made available to the stakeholders and the practices of corporate disclosure in annual accounts. Annual reports are indeed the company's most significant reporting event. The financial statements attempts to meet the information needs of not only the shareholders but also other major stakeholders, the biggest challenge the management faces while preparing the annual report is balancing the information needs of the various stakeholders.
\end{abstract}


Companies are currently forced to disclose their financial information to their stakeholders'inorder to gain goodwill and gain more capital for further development. Companies consider financial reporting as a tool to hold existing shareholders and promote stakeholders to become a shareholder. It is evident from thevarious medium, that financial reporting from companies has increased, but it is still a question whether the stakeholders use this information as a valuable resource.

\section{Background of the study}

The separation of the management and ownership of the modern public corporation creates many problems like aconflict of interest between the manager and the owners. Numerous corporate scandals involving leading public firms such as Enron, world com, Xerox, Tyco, Satyam have adversely affected financial markets and stakeholder's confidence.

Falsified financial statements are not a new spectacle. The common sham financial activities included asset and revenue exaggeration, the camouflage of liabilities and expenses, wrong revenue recognition,insufficient disclosures.

Fraud means a measured misstatement or exclusion of material fact or accounting data, which leads to a distortion of actual worth.

\section{Statement of the problem}

This study attempts to assess whether the changes in the Corporate Financial Reporting, new regulations, and standards imposed have a significant impact on the stakeholders' confidence and satisfaction or not.This bending of accounting rules and biased assumptions of accounting provisions intrigued me about how the annual accounts are manipulated to such extents despite the involvement of various independent examiners such as the external auditor and its detrimental impact on not only the shareholders but the various other stakeholders of the company.

\section{This study explores the specific issue}

The impact of the financial reports on the stakeholders' confidence and satisfaction.

Previous studies and analysis oftherelevant topic state that there exists asignificant relationship between standard financial reporting practices and their impact on the stakeholder's confidence and satisfaction. 


\section{Literature Review}

\section{The Corporate Report, London $1975^{1}$}

The basic philosophy of the report was that financial statements should be adequate for reference by potential users. The Corporate Report suggested the need for the following reports

$\checkmark$ A statement of value added to show how the revenue was generated and distributed among various stakeholders.

$\checkmark$ An employee report detailing the turnover and compensation packages to ward off ambiguity.

$\checkmark$ A statement of money exchanges with the government like the various taxes that have to be paid.

$\checkmark$ A statement of transactions in foreign currency.

$\checkmark$ A statement showing the future prospects and forecasts.

$\checkmark$ A statement of corporate objectives showing management’s policy and strategy.

\section{Financial Accounting Standard Board (FASB)-1978 ${ }^{2}$}

The FASB emphasized the use of financial reporting for different classes of users and not for the creditors and the investor's only. Predictability was also included as an element of the objectives of accounting information. The purpose was to provide useful information for making business and economic decisions by the parties having an interest in the organization.

\section{The International Accounting Standards Committee (IASC)-1989}

In the year 1989, The IASC issued a framework for the preparation and presentation of financial statements.According to this framework, the objectives of the financial statements is to report information about the financial position, performance,and changes in financial position of an enterprise that is useful to a wide range of users in making economic decisions.(Porwal, 2007) ${ }^{10}$

\section{Accounting Standards Board-1991 ${ }^{4}$}

The Accounting Standards Board of the U.K. issued a "Statement of Principles" in July 1991. 
It holds that the main objective of financial statements is to provide data about the financial position, performance and the capacity of the company to meet the needs of its diverse users and stakeholders in making economic decisions.(Porwal, 2007).

The proper preparation and presentation of the general purpose financial statements will lead to the fulfillment of the basic objective of financial statements.(Singh, 2009)

\section{Institute of Chartered Accountants of India (ICAI)-2000}

Institute of Chartered Accountant of India (ICAI) has also contributed to the making of the objectives of financial reporting. The Accounting Standard Board (ASB) of the Institute of Chartered Accountants of India (ICAI) issued a framework for the preparation and presentation of financial statements in July 2000.

\section{Studies on financial reportingand accounting practices}

Various studies have been conducted in India and abroad related to different aspects of the disclosure. The pertinent literature related to financial reporting have been reviewed

Asunder

Gupta (1977), ${ }^{6}$ went through the financial reporting practices of India, Australia. USA and UK the results showed that the reports did not disclose the requisite amount of information required in today's busy and complex conditions. The author stressed that the financial reports should aim more at meeting the special needs of the shareholders. He also stated care should be taken that disclosures should be increased but they should be relevant as well to users of the financial statements and the cost incurred in making the extra disclosures or special segment reports for specific users should also be justified.

Singh and Bhargava(1978), ${ }^{7}$ Studied the disclosure practices of 40 public sector companies. The findings revealed that the quality of disclosure varied not only with the industries but also with the surroundings and only with more disclosure and transparency can the public sector enterprises improve their images. The disclosures are divided into subparts: - mandatory and voluntary and the findings showed that mandatory disclosures were made by most enterprises but 
there was a lot of discrepancy in the voluntary disclosures because of proper guidelines in the area.

Wood and Wilkinson (1985), ${ }^{8}$ studied the disclosure practices of general insurance companies Of UK. The study revealed that heavy estimates were present in the financial statements of the general insurance companies and there seemed a need for a recognized standard. As many of the transactions in the insurance companies are based on various methods of forecasts and contingencies which may give rise to estimates and create ambiguities in the numbers. Suggestions were also made to prepare the financial statements of insurance companies with the consistent accounting policies in case it is not followed then explanation regarding the same has to be mentioned.

Chakrabarti(1990), ${ }^{9}$ studied the annual reports of 50 companies for 1980 and 1985 to measure the recent developments in corporate financial reporting in India. An index of 23 items was constructed and the suggestions made after the study was to suggest that disclosure of significant accounting policies should be made obligatory to increase the reliability and credibility of the annual reports. As changes in the accounting policy may have an impact on various interconnected transactions and may also have a retrospective effect what is advised as per conservatism principle is that firstly the principles if possible should not be changed frequently unless required by a law or statute or it leads to the better presentation of the matter. If any changes have been made in the accounting policies then the changes have to be stated and valid reasons have also to be enumerated.

Rathod(1990), ${ }^{10}$ examined the recent trends in the financial reporting in the corporate sector in India. The study was based on the annual reports of 10 Public limited companies for one year; all the companies give the relevant information required.At the time of the annual report, the director's report was considered the main part thus concluding that financial reporting has got a lot of importance in the present era.

Chander (1992), ${ }^{11}$ made a comparison of the disclosures made by the public and private sector companies after scanning the annual reports and preparing an index of 98 disclosure items. The findings of the study showed that a significantly better disclosure was made in the public sector as compared to the private sector hence the findings that public sector companies comparatively 
take more time in finalizing their annual reports as compared to private sector companies.The norms regulating the private sector are comparatively less as compared to the public sector regarding the level and quantum of disclosure items. It was observed that in akes both sectors followed the mandatory requirements religiously but cut back some slack when it came to voluntary disclosures. The stakes involved in the public sector are comparatively more and a number of users have to be serviced sometimes even with separate reports hence the public sector undertakings showed a better level of disclosure.

Bhattar(1995), ${ }^{12}$ studied the relevance and use of Published accounting information for investors in the study. The findings of the study revealed a wide gap between information reports of the companies and the informational needs of the individual shareholder.The conclusion reached was that more disclosure will enhance the confidence of the shareholders and in turn, the credibility of the company will also be enhanced.

\section{Research Design used}

In this study, the objective is to measure the impact of financial reporting on the stakeholder's confidence and satisfaction. Quantitative Analysis:- In this phase, a questionnaire has been formulated and sent to the various stakeholders of the companies that are listed on the National Stock Exchange (NSE) and once their responses were collected the various tools wereused to quantify the data collected.

Development of Simplified Framework: - The findings provide the information required to be able to develop a simplified framework. The decision to select the approach listed above has been determined by the objective of the study, the nature of the concept that has to be investigated and the different research methodologies that are available. The questionnaire includesindicators that have been discovered in the literature review..

\section{Sample size}

The target population for the quantitative research will include stakeholders of the listed company. As stated above, the population of interest for this study includes Companies listed on the NSE and its various stakeholders. The reason for this selection is listed companies are required to publish an annual report every year.

The population is summarized as follows 
Stakeholders of listed companies- 350 total

\section{Data Collection Method}

The data was collected by means of a questionnaire. The main objective of the research is to determine the impact of financial reporting on stakeholders' confidence and satisfactions. The questionnaire will allow us to determine the topics for future reporting including the main sections that should be included in future reports, and the most important performance indicators that should be included in future reports.

A Likert scale was used for the respondents to classify their responses. The questions provided 5 possible responses namely

$\begin{array}{ll}\text { Strongly agree } & 5 \\ \text { Agree } & 4 \\ \text { Neutral } & 3 \\ \text { Disagree } & 2 \\ \text { Strongly disagree. } & 1\end{array}$

The questionnaire is structured in three parts in order to be able to analyze the responses. The 3 parts are as follows Part 1-In this part,we requested respondents to provide information about their socio-economic background. Part 2-In the second part aspire to measure the level of stakeholder's confidence. Part 3- In this final part, weaspire to measure financial reporting variables. Responses to the questions in this part of the questionnaire would ultimately allow us to develop a simplified framework forreporting the stakeholder's confidence and satisfaction.

\section{Analyzing the Data}

Firstly, the reliability of the questions that are included in the questionnaire was tested for reliability using Cronbach's alpha. If the measure of reliability in this analysis exceeds 0.7, it will be accepted as good reliability (Page and Meyer, 2005). The analysis was carried out using Confirmatory Factor Analysis and Structured Equation Modelling.

\section{General Demographic Profile of Respondents}

Respondent's demographic profile has been given in the Exhibit1. The Exhibit shows that out of the total sample of 319 respondents, 234 (i.e.73.4\%) are male whereas rest 85 (26.6\%) are female respondents. Thus the sample skewed towards male respondents. Age distribution of the sample shows that majority of the respondents belongs to age group 20-30 years (40.4\%) and 30-40 
years $(45.5 \% \%)$ and $11.3 \%$ of the total respondents are in the age group of $40-50$ years whereas only $2.8 \%$ respondents were reported to be the age of 50 years or more. 56 respondents out of total sample (i.e. 17.9\%) are single and 156 (48.9\%) are married without children whereas 106 (i.e. 33.2.\%) are married with children and one respondent was reported as divorced. Majority of the respondents 285 (89.3\%) are having a nuclear family and only 34 (10.7\%) have a joint family. Respondent's educational profile shows that majority of the respondents are either Graduate (49.2\%) or Postgraduate (38.6\%).

Exhibit 1 Demographic Profile of Respondents

\begin{tabular}{|c|c|c|c|}
\hline Variable & Category & Frequency & Percentage \\
\hline & Male & 234 & 73.4 \\
\hline \multicolumn{4}{|l|}{ Gender } \\
\hline & Female & 85 & 26.6 \\
\hline & Under 20 & 0 & 0.0 \\
\hline & $20-30$ & 129 & 40.4 \\
\hline \multirow[t]{5}{*}{ Age } & $30-40$ & 145 & 45.5 \\
\hline & $40-50$ & 36 & 11.3 \\
\hline & 50 and above & 9 & 2.8 \\
\hline & Single/Never Married & 56 & 176 \\
\hline & Married without children & 156 & 48.9 \\
\hline Marital & Married with children & 106 & 33.2 \\
\hline \multirow[t]{4}{*}{ Status } & Widow & 00 & 0.0 \\
\hline & Separated & 00 & 0.0 \\
\hline & Divorced & 01 & 0.3 \\
\hline & Nuclear & 285 & 89.3 \\
\hline \multirow{2}{*}{\multicolumn{4}{|c|}{$\begin{array}{l}\text { Family } \\
\text { Type }\end{array}$}} \\
\hline & & & \\
\hline & & & \\
\hline & Less than High School & 0 & \\
\hline & High school & 0 & \\
\hline \multirow[t]{6}{*}{ Education } & Intermediate & 6 & 1.9 \\
\hline & Graduate & 157 & 49.2 \\
\hline & Post-Graduate & 123 & 38.6 \\
\hline & Ph.D. & 5 & 1.6 \\
\hline & Technical Education (B Tech/BE) & 10 & 3.1 \\
\hline & $\begin{array}{l}\text { Professional degree (CA, CS, MBBS, Lawyer, } \\
\text { Professor) }\end{array}$ & 18 & 5.6 \\
\hline
\end{tabular}




\begin{tabular}{|c|l|c|c|}
\hline & & & \\
\hline & $0-5$ & 147 & 46.1 \\
\hline Experience & $6-10$ & 117 & 36.7 \\
\hline In years & $11-15$ & 28 & 8.8 \\
\hline & $16-20$ & 11 & 3.4 \\
\hline & $21-15$ & 13 & 4.1 \\
\hline & 26 and above & 3 & 0.9 \\
\hline
\end{tabular}

\section{Confirmatory Factor Analysis}

Confirmatory factor analysis was conducted on the data set to test the goodness of fit of the data and to assess validity and reliability of the factors under study."Confirmatory factor analysis is an increasingly popular multivariate modeling technique used to test specific hypotheses about the factor structure underlying a correlation or covariance matrix (Mulaik, 1988, cited by Damos, 1991)”. Generally in comparison with exploratory factor analysis "confirmatory factor analysis is used where measures ahs a known factor structure (Bollen, 1989; Gorsuch, 1983; Jöreskog\&Sörbom, 1993, Hoare, 2006)”

The measurement model comprising three main constructs of the study - satisfaction, financial reporting and stakeholder confidence was tested using Amos 20.0. Satisfaction (4 variable) and financial reporting (15 variables) were treated as zero order construct, whereas employee confidence was treated as second-order construct which comprised of reliability (4 variables), corporate image (6 variables), commitment (8 variables), communication (5 variables) and trust (11 variables) .

\section{Model Fit}

In order to test the goodness of fit of the measurement model, various fit indices were used along with Chi-square value as shown in the Exhibit 2. According to Hair et al. (2010) Chi-square value should be less than 5 and in the present case, the value is 1.882 which is less than the recommended value, therefore is acceptable. Further Comparative Fit Index (CFI) and TuckerLewis Index (TLI) values should be more than 0.9 Hair et al. (2010). The exhibit below shows that both the value CFI (0.923), as well as TLI (0.919), are well above the threshold value. Root Mean Square Approximation (RMSEA) index should be below 0.1 or 0.08 and in this case, this value is 0.053 which is less than the suggested value and therefore is acceptable. Thus all the fit 
indices are well within the range or threshold suggested by Hair et al. (2010) and therefore it can be concluded that the measurement model has produced a good fit.

\section{Exhibit 2 Model Fit Indices}

\begin{tabular}{|l|l|l|l|l|}
\hline Fit Indices & CMIN/df & CFI & TLI & RMSEA \\
\hline Recommended Value & $<5$ & $>0.9$ & $>0.9$ & $<0.1$ \\
\hline Model Value & 1.882 & 0.923 & 0.919 & 0.053 \\
\hline
\end{tabular}

\section{Validity and Reliability}

Once the goodness of fit has been found acceptable, now it is necessary to assess the validity and reliability of the factors under study.

\section{Reliability}

Generally, the reliability of the factors is assessed using Cronbach Alpha. However, there is another measure of internal consistency (reliability) known as Composite reliability (CR) shown in the Exhibit 3. "Composite reliability is the measure of reliability since Cronbach's alpha sometimes underestimates the scale reliability (Anh et al., 2017).”According to Nunnally (1978), for a measure to be the reliable value of composite reliability (CR) should be greater than 0.7. The Exhibit below shows that CR values for all three factors - Financial Reporting (0.958), Satisfaction (0.899) and Confidence (0.835) are above the recommended value 0.7 and therefore all three factors are reliable and internally consistent.

Exhibit 3 Reliability and Validity (Convergent and Discriminate)

\begin{tabular}{|l|l|l|r|r|r|}
\hline & CR & AVE & $\begin{array}{l}\text { Financial } \\
\text { Reporting }\end{array}$ & $\begin{array}{l}\text { Stakeholder's } \\
\text { Satisfaction }\end{array}$ & $\begin{array}{l}\text { Stakeholder's } \\
\text { Confidence }\end{array}$ \\
\hline $\begin{array}{l}\text { Financial } \\
\text { Reporting }\end{array}$ & 0.958 & 0.603 & $\mathbf{0 . 7 7 7}$ & & \\
\hline Satisfaction & 0.899 & 0.692 & 0.273 & $\mathbf{0 . 8 3 2}$ & \\
\hline Confidence & 0.835 & 0.508 & 0.451 & 0.543 & $\mathbf{0 . 7 1 3}$ \\
\hline
\end{tabular}




\section{Validity}

The validity of the factors under study is assessed using two statistical measures convergent validity and discriminant validity.

Convergent validity refers to the extent to which the observed variables converge to the corresponding construct/factor (Hair et al., 2010). "Convergent validity refers to the degree to which the measurement outcomes representing a construct agree (are consistent) with other indicators of the same construct (Teddlie\&Tashakkori, 2009)".Generally, convergent validity is assessed using Average Variance Extracted (AVE). If the value of AVE for a given construct is more than 0.5, it means that the construct ensures convergent validity (Fornell and Larcker, 1981). Exhibit 3 gives the value of AVE for all three constructs under study - Financial Reporting (0.603), Satisfaction (0.692) and Confidence (0.508). All three values are above the threshold value 0.5 as suggested by (Fornell and Larcker, 1981) and therefore these constructs confirm convergent validity.

Another type of validity is called discriminant validity which refers to the extent one factor is distinct from other (Hair et al., 2010). It indicates that factors are truly distinct or different from each other. Discriminant validity is assessed by comparing the square root of AVE for a given factor with the correlation between this factor and other factors. According to (Fornell and Larcker, 1978), if the square root of AVE is greater than the correlation with other factors, it means that factor is distinct from other factors and thus ensures discriminant validity. In Exhibit 3 , the square root of AVE for each factor is given in the diagonal (bold values) and values below the diagonal are inter-factor correlation. It is clear from the Exhibit that square root of AVE is more than the corresponding correlation values for each factor. Therefore factors under study have discriminant validity. 


\section{Exhibit 4 Measurement Model (Confirmatory Factor Analysis)}

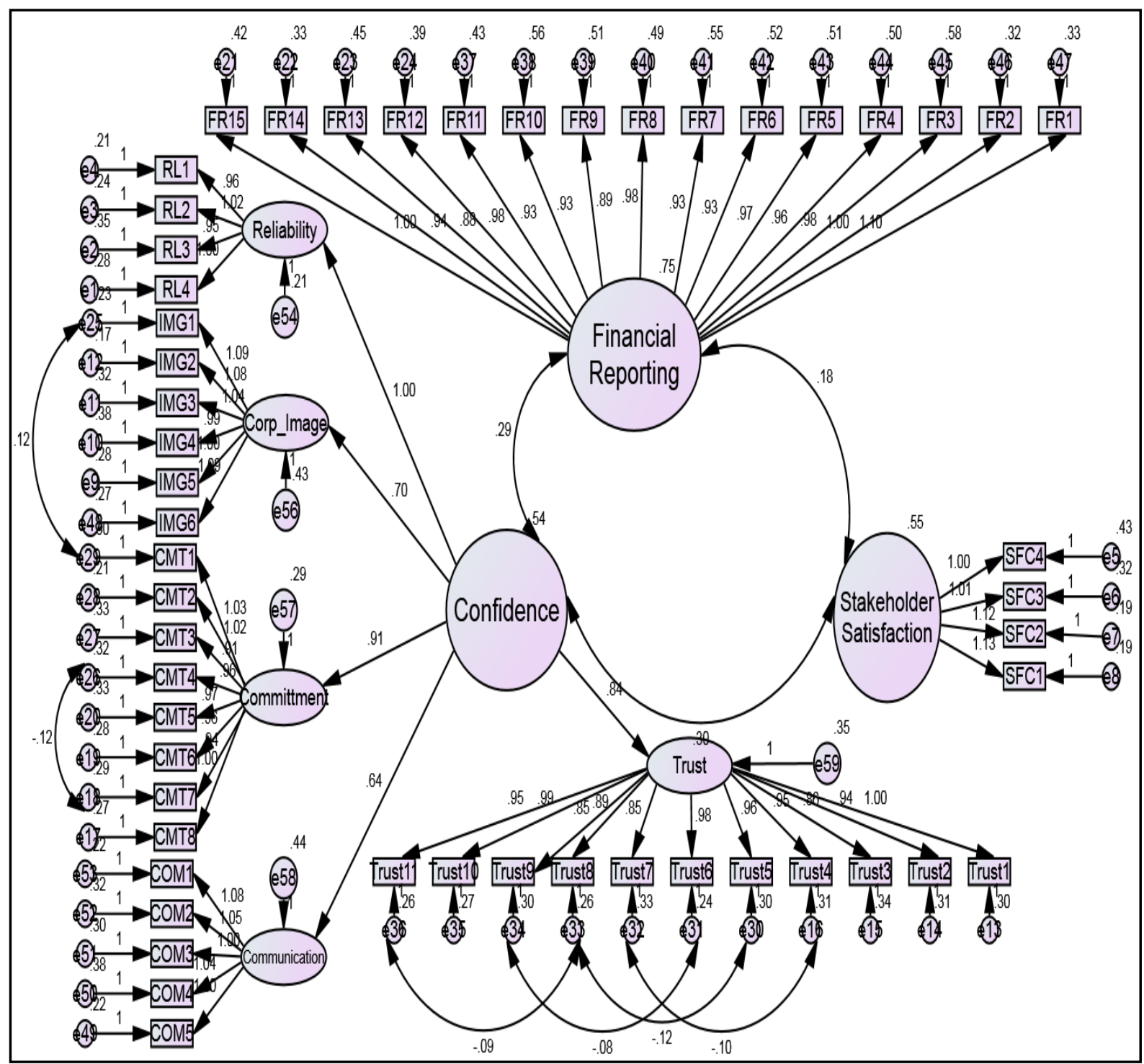

\section{Structural Model}

After conducting confirmatory factor analysis on the measurement model and confirming reliability and validity of the factors under study, in the next step, path analysis is conducted with the structuralmodel by drawing the appropriate path relationship among the factor. The goodness of the structural model is tested using various fit indices as discussed in the previous section. Exhibit 5 gives values of model fit indices of the structural model. All the fit indices values are within the recommended range suggested by Hair et al. (2010); therefore the structural model has also produced goodness of fit. 


\section{Exhibit 5 Model Fit Indices}

\begin{tabular}{|l|l|l|l|l|}
\hline Fit Indices & CMIN/df & CFI & TLI & RMSEA \\
\hline Recommended Value & $<5$ & $>0.9$ & $>0.9$ & $<0.1$ \\
\hline Model Value & 1.880 & 0.923 & 0.919 & 0.053 \\
\hline
\end{tabular}

\section{Path Results (Hypothesis Testing)}

The results of hypotheses testing i.e. path analysis have been shown in the Exhibit9. Following two hypotheses had been conceptualized for the present study

Hypothesis 1

Null Hypothesis- Financial Reporting has no significant impact on stakeholder's confidence

Alternate Hypothesis- Financial Reporting has a significant impact on stakeholder's confidence

Results of hypothesis testing for above null hypothesis shows that (Exhibit 6) the corresponding test statistics $($ C.R. $=7.119$, S.E. $=0.054)$ is significant as the corresponding p-value is very low compared to critical value 0.05 (at 95\% level of significance). Thus above null hypothesis is rejected and the alternate hypothesis assuming a significant impact of financial reporting on stakeholder's confidence is accepted. Further $\mathrm{R}^{2}$ value shows that financial reporting explains 20.75 of the total variance of stakeholder's confidence.

\section{Exhibit 6 Results of Hypothesis Testing}

\begin{tabular}{|ll|r|r|r|c|c|l|l|}
\hline & Estimate & S.E. & C.R. & $\mathbf{P}$ & $\boldsymbol{\beta}$ & $\mathbf{R}^{\mathbf{2}}$ & Result \\
\hline Confidence <--- $\begin{array}{l}\text { Financial } \\
\text { Reporting }\end{array}$ & 0.385 & 0.054 & 7.119 & $* * *$ & 0.455 & 0.207 & Supported \\
\hline Satisfaction <---- $\begin{array}{l}\text { Stakeholder's } \\
\text { Confidence }\end{array}$ & 0.555 & 0.070 & 7.941 & $* * *$ & 0.546 & 0.298 & Supported \\
\hline
\end{tabular}

\section{Hypothesis 2}

Null Hypothesis Stakeholder's Confidence has no significant influence on the Stakeholder's Satisfaction. 
Alternate Hypothesis Stakeholder's Confidence has a significant influence on the Stakeholder's Satisfaction.

The results given in Exhibit 6 shows that the above null hypothesis is rejected as the corresponding test value $($ C.R. $=7.941$, S.E. $=0.070)$ is significant as the corresponding p-value is less than the threshold value 0.05. Therefore, the alternate hypothesis that Stakeholder's Confidence has a significant influence on Stakeholder's Satisfaction, is accepted.

Thus from the above statistical analysis, it is clear that financial reporting affects stakeholder's confidence in the firm which consequently affects stakeholder's overall satisfaction for the firm.

\section{Exhibit 7 Structural Model}

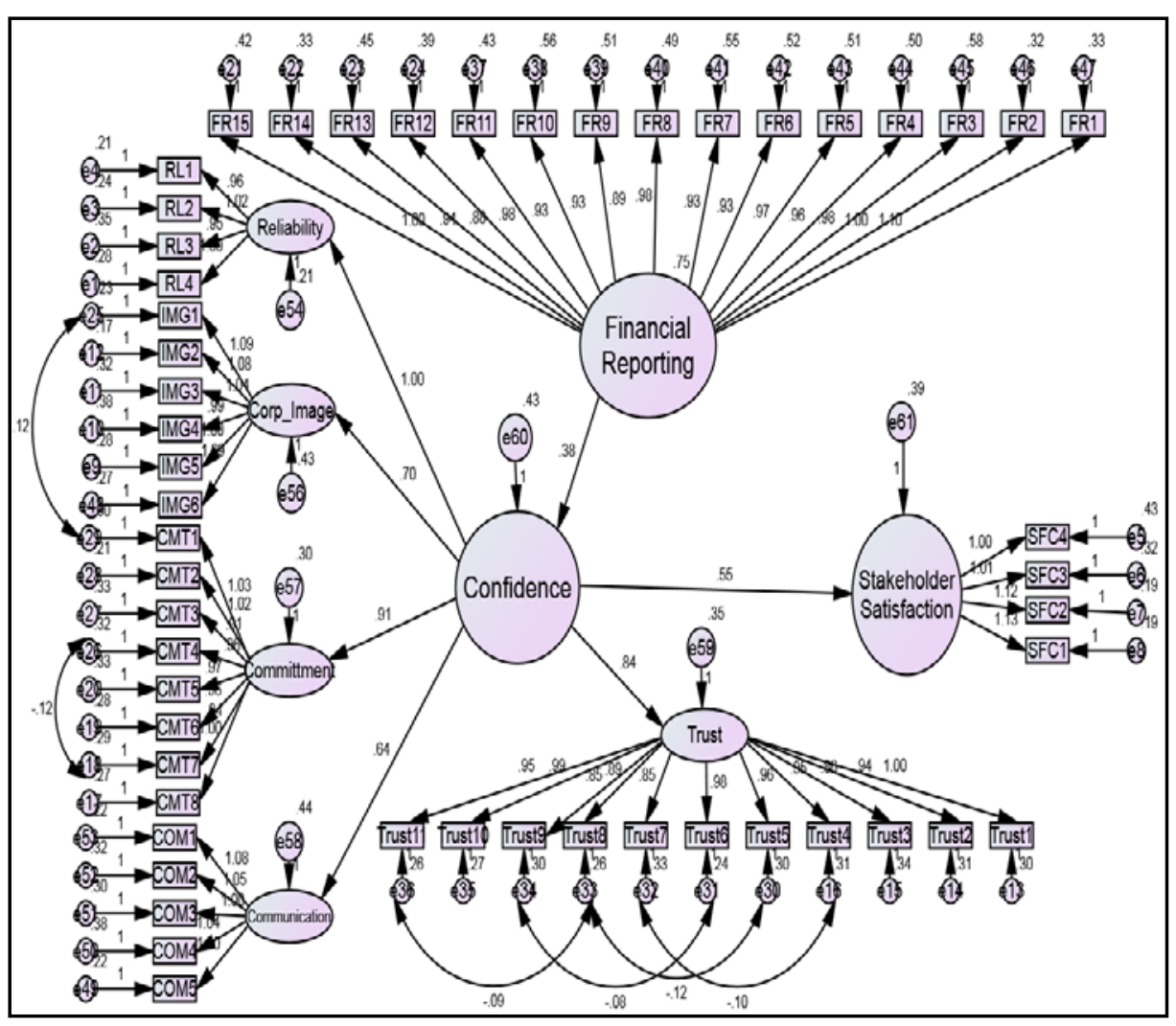




\section{Findings, Conclusion and Suggestions}

After conducting analyses and making conclusions some meaningful facts have come to the knowledge. All such facts have been mentioned here. While conducting research it was experienced that some more or new things could have been added at different levels of the research.

\section{Findings of Review of Literature}

$\checkmark$ Companies have a responsibility not only towards shareholders but also to all the stakeholders.

$\checkmark$ Huge corporate and accounting frauds by giant companies have shaken the faith and the confidence of the stakeholders in the recent past.

$\checkmark$ Annual Report has emerged as the most important document on which the stakeholders rely and derive their confidence from.

$\checkmark$ Corporate governance report and management discussion and analysis report cater to the stakeholder's interest the most out of all the other major mandatory reports.

$\checkmark$ Instances of companies which have evaded the financial reporting mandatory disclosures in the past have come to light and have cost not only the investors and other stakeholders but the entire economy at large. (eg. Satyam)

$\checkmark$ Slow but steady improvement is there in the corporate reporting scenarios as strict and stringent rules are being put in place by all the governing and regulatory bodies involved.(aspect discussed in chapter 3).

$\checkmark$ Stakeholder's inclusive policies are being brought out by companies.

$\checkmark$ Stakeholder's grievance redressal committees are also being formed by various companies under the Company Act 2013.

$\checkmark$ The Stakeholder Groups pertinent to the study have been identified and used as the respondent group.

\section{Findings of Pilot Study}

A pilot study was conducted with 50 responses and reliability (internal consistency) of all the constructs under study was assessed using Cronbach alpha. According to Hair et al. (2010) for a construct to be reliable Cronbach alpha value for each construct should be more than 0.7.Cronbach alpha value for each construct is more than the critical value 0.7 , therefore all the constructs have internal consistency and hence are reliable. 
Hence after conducting the pilot study the validity and reliability have been confirmed by the questions and even their inter-relationship and association among themselves have been confirmed. After the positive response to most questions, they were accepted and the ones with negative responses were removed from the questionnaire

\section{Findings of Research Analysis}

\section{Findings of Confirmatory Factor Analysis}

\section{Factors involved}

1 The first factor was comprised of fifteen variables FR1, FR2, FR3.....FR15 which describe various aspects of financial reporting. Thus this factor may be named as 'Financial Reporting'.

2 The second factor consists 11 variable (Trust1, Trust2,.....Trust11) describing the trust of a stakeholder in the firm. This factor has been named as 'Stakeholder's Trust'.

3 The third factor has eight variable (CMT1, CMT2,...CMT8) which gives details about the 'stakeholder's commitment'.

4 The fourth factor constitutes six variables (IMG1, IMG2,....IMG6) which represents stakeholder's perception about 'Corporate Image’ of the firm.

5 The fifth factor consists of five variables (COM1, COM2,...COM5) which describe the level of ‘Communication' between stakeholder and firm.

6 The sixth factor which represents 'Satisfaction Level' of the stakeholder consists four observed variables (SFC1, SFC2,...SFC4).

7 The seventh and last factor is the stakeholder's perception of the 'Reliability' of the firm. This factor comprises four observed variables (RL1, RL2,..RL4).

Confirmatory factor analysis was conducted on the data set to test the goodness of fit of the data and to assess validity and reliability of the factors under study. The measurement model comprising three main constructs of the study - satisfaction, financial reporting and stakeholders' confidence was tested using Amos 20.0. Satisfaction (4 variable) and financial reporting (15 variables) were treated as zero order construct, whereas employee confidence was treated as second-order construct which comprised of reliability (4 variables), corporate image (6 variables), commitment (8 variables), communication (5 variables) andtrust (11 variables). 
All three factors are reliable and internally consistent.

\section{Findings of Structured Equation Modelling}

After conducting confirmatory factor analysis on the measurement model and confirming reliability and validity of the factors under study, in the next step, path analysis is conducted with the structural model by drawing the appropriate path relationship among the factor.

Hypothesis 1 : The null hypothesis is rejected and alternate hypothesis assuming a significant impact of financial reporting on stakeholder's confidence is accepted.

Hypothesis 2:Therefore, the alternate hypothesis that Stakeholder's Confidence has a significant influence on Stakeholder's Satisfaction, is accepted.

Thus from the above statistical analysis, it is clear that financial reporting affects stakeholder's confidence which consequently affects stakeholder's overall satisfaction.

Thus after the complete process of literature review, pilot study, studying the various acts rules and regulations, conducting the various qualitative and quantitative analysis the following model has been developed by us. 


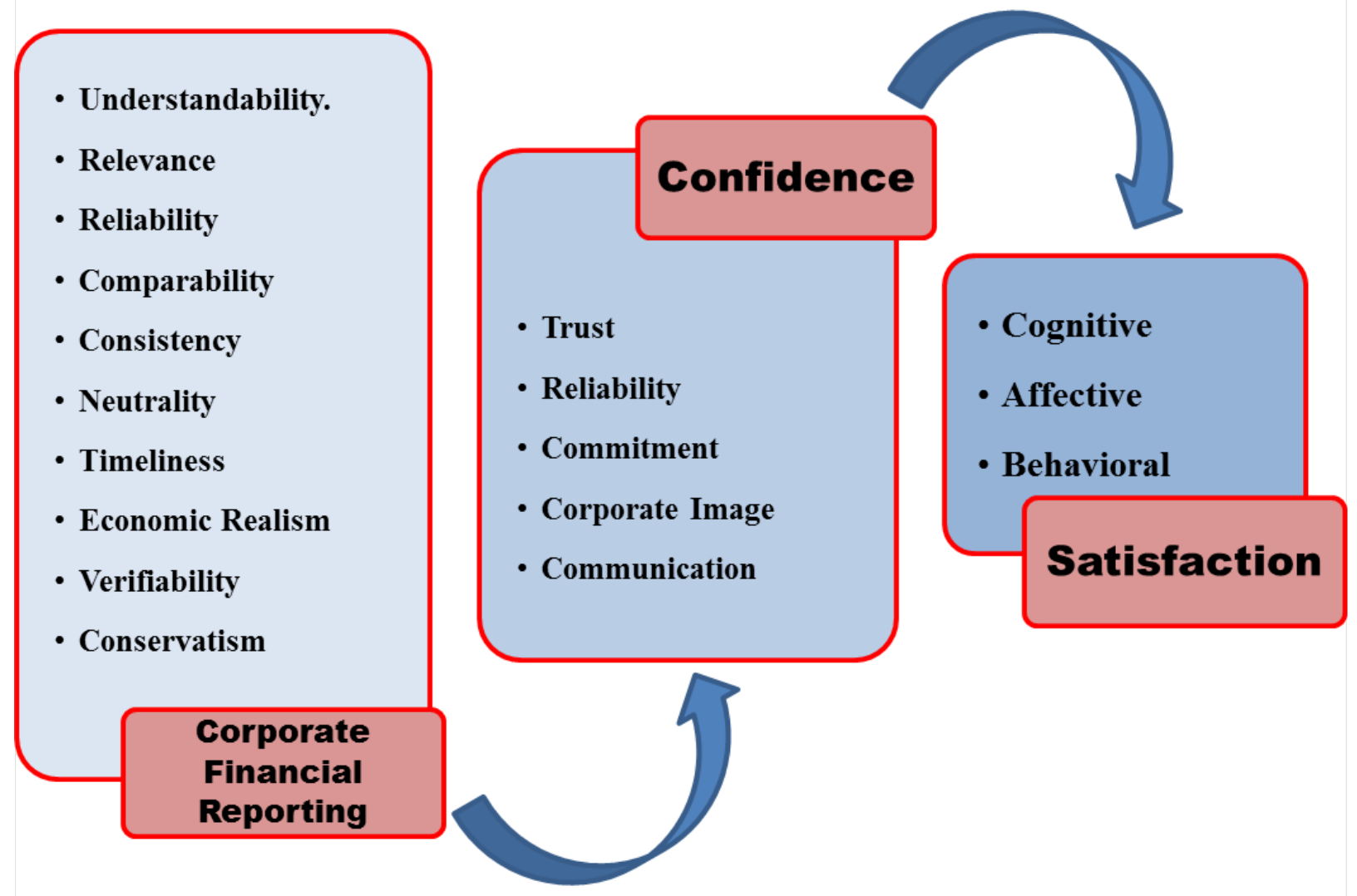

The model we have arrived at states that when all the elements stated therein of Corporate Financial Reporting are followed ethically and honestly it has a significant impact on the stakeholders' confidence and ultimately leads to satisfaction.

\section{Conclusion}

In a perfect world, investors, board members, and executives would have full confidence in companies' financial statements. They could rely on the numbers to make intelligent estimates of the magnitude, timing, and uncertainty of future cash flows and to judge whether the resulting estimate of value was fairly represented in the current stock price. And they could make wise decisions about whether to invest in or acquire a company, thus promoting the efficient allocation of capital.Unfortunately, that's not what happens, for several reasons. First, corporate financial statements depend on estimates and judgment that can be quite wrong, even when made in good faith. Second, standard financial numbers 
intended to enable comparisons between companies may not be the most accurate way to judge the value of any particular company-this is especially the case for innovative firms in fast-moving economies-giving rise to unofficial measures that come with their own problems. Finally, managers and executives regularly run into strong inducements to purposely give a jab of blunder into financial statements

Despite the number of reforms, corporate accounting remains murky. Companies continue to find ways to cheat the system, while the appearance of online platforms, which has intensely altered the economic environment for all businesses, has provided stark relief from the inadequacies of customary performance indicators. This study looks at the most important developments of financial reporting in recent years, particularly the impact of the new rules on the stakeholders' confidence and satisfaction.

\section{References}

1. The Corporate Report, London (1975),Accessed December, 2015.

2. Financial Accounting Standard Board (FASB). Accessed march, 2016.

3. The International Accounting Standards Committee (IASC)-1989, Accessed December 14, 2015.

4. Accounting Standards Board-1991, Accessed December, 2015.

5. Institute of Chartered Accountants of India (ICAI)-2000(14), Accessed December 14, 2015.

6. Gupta, N.D., (1977). Financial Reporting in India, Sultan Chand,and Sons, July.

7. Singh, D.R. and Bhargava, S.K. (1978), Quality of disclosure in the Public Sector Enterprise, Vikalpa 3(4):257.264.

8. Wood, G.N.C., and Wilkinson, R.C. (1985). Disclosure by General Insurance Companies Presented to the Institute of Actuaries Students Society, May 14, www.sias.org.uk/papers/disclodure.

9. Chakrabarti, Kumar P., (1990), Corporate Financial reporting in India-New Perspectives In M.Sayeed (Ed.), Corporate Financial Reporting, ISBN 81-7041-348-6,p.37-335.

10. Rathod, R.K., (1990), Recent Trends in Financial reporting in Corporate Sector in India, in M In Sayeed (Ed.), Corporate Financial Reporting, ISBN 81-7041-348-6,p. 39-49. 
11. Chandar, Dinesh S.K., (2007). Corporate attribute and compliance with Accounting Standards in India: An Empirical Study. The Icfai Journal of Accounting Research VI: 3651.

12. Bhattar, M.M., (1995), Corporate Publishing Accounting Information and Investor. An Empirical Study, ISBN 81-900422-9-7, Books Treasure, Jodhpur, India

13. Hair, J., Black, W. C., Babin, B. J. \& Anderson, R. E., (2010). Multivariate Data Analysis (7th Ed.). New Jersey Prince Hall.

14. Fornell, C., and Larcker D., F. (1981). Evaluating structural equation models with unobservable variables and measurement error. Journal of marketing research (1981) 3950.

15. Nunnally, J C (1978). Psychometric Theory, New York; McGraw-Hill.

16. Damos, D. (Ed.). (1991). Multiple task performance. CRC Press.

17. Mulaik, S. A. (1988). Confirmatory factor analysis. In Handbook of multivariate experimental psychology (pp. 259-288). Springer, Boston, MA.

18. Hoare, C. (Ed.). (2006). Handbook of adult development and learning. Oxford University Press.

19. Bollen, K. A. (1989). A new incremental fit index for general structural equation models. Sociological Methods \& Research, 17(3), 303-316.

20. Gorsuch, R. L. (1983). Factor analysis, 2nd. Hillsdale, NJ,LEA.

21. Jöreskog, K. G., \&Sörbom, D. (1993). LISREL 8,Structural equation modeling with the SIMPLIS command language. Scientific Software International.

22. Anh, L. H., Dong, L. S., Kreinovich, V., \&Thach, N. N. (Eds.). (2017). Econometrics for Financial Applications (Vol. 760). Springer.

23. Teddlie, C., \&Tashakkori, A. (2009). Foundations of mixed methods research Integrating quantitative and qualitative approaches in the social and behavioral sciences. Sage. 